\title{
CONFERENCIAS
}

\section{TRATAMENTO DOS TUMORES CEREBRAIS PELA RADIOTERAPIA}

\section{MARGARE'T TOODD *}

No tratamento dos tumores do sistema nervoso central, a radioterapia, com a conhecida exceção do meduloblastoma, é associada à cirurgia. O papel de um associado, entretanto, pode ser importante e a irradiação, minuciosamente preparada, pode conduzir, em certos tipos de tumores, ao desaparecimento total dos sintomas durante certo tempo e mesmo, às vêzes, à cura completa. Neste domínio, no entanto, a experiência clínica do radioterapeuta é limitada, e as verificações clínicas e operatórias do neurocirurgião devem guiá-lo. Ele deve levar em conta, também, os achados patológicos e a histologia do tumor, pois o tratamento deve ser feito de acôrdo con a radiossensibilidade provável do tumor. Se lhe faltar esta informação, mas se o estado geral do doente é satisfatório, o radioterapeuta deve dar a êste último o benefício da dúvida e aplicar o tratamento, esperando que o tumor pertença a um dos grupos radiossensíveis.

Do ponto de vista do radioterapeuta, há, grosseiramente, quatro grupos de casos nos quais, sendo diagnosticado um tumor cerebral, foi requisitada sua ação terapêutica: 1. Casos nos quais o crânio foi aberto e o tumor, mais ou menos completamente extirpado; 2. Casos nos quais foi praticada uma trepanação descompressiva, sendo verificada a existência de um tumor inoperável, do qual foi possível ou não fazer a biópsia; 3. Casos cuja gravidade afastou tôda a possibilidade da trepanação; 4. Casos anteriormente tratados pela cirurgia e que recidivaram, já não sendo susceptíveis de nova intervenção.

$\mathrm{Na}$ qualidade de radioterapeuta, não procurarei discutir a classificação anátomo-patológica dos tumores cerebrais. Cushing e Eisenhardt fizeram uma lista, que não compreende menos de nove tipos principais de meningiomas, com 20 grupos secundários; além disso, autoridades de primeira plana divergem no diagnóstico histológico de quase todos os tumores cerebrais. O que nos interessa, apenas, é saber quais são os tumores susceptíveis de tratamento pela radioterapia. Com êste intuito, a classificação que julgamos mais útil é a de Dott e McWhirter, publicada em 1946. Nós a modificamos ligeiramente, para melhor clareza:

Conferência realizada na Sociedade de Neurologia do Rio de Janeiro, em 9 setembro 1948.

* Vice-Diretora do Instituto de Rádio de Manchester (Inglaterra). 
Grupo 1 - Tumores radiorresistentes (astrocitomas, ependimomas, oligodendrogliomas, neuromas, meningiomas de formas resistentes);

Grupo 2 - Tumores radiossensiveis localizados (neuroepiteliomas, hemangioblastomas, meningiomas de formas sensíveis);

Grupo 3 - Tumores radiossensiveis com metástases (meduloblastomas, ependimoblastomas, papilomas malignos do plexo coriódeo, pineoblastomas);

Grupo 4 - Tumores resistentes malignos (glioblastomas, astroblastomas) ;

Grupo 5 - Tumores da hipófise (tumores resistentes cromófobos, tumores menos resistentes cromófilos, tumores basófilos de resistência desconhecida).

Nesta classificação deve-se notar que os meningiomas aparecem duas vêzes, tanto no grupo dos tumores resistentes, como no grupo dos tumores sensiveis. Parece que existem dois tipos de meningiomas cuja reação à irradiação é diferente, mas que não se podem diferençar pelo exame histológico. Dott procurou estabelecer a percentagem dos meningiomas sensíveis, avaliando-a em 43\%. Este autor os descreve assim: "Os meningiomas com hiperostose extensa são sensíveis. Os meningiomas, cujo afluxo de sangue não vem da dura-máter, são radiorresistentes. Aquêles cujo afluxo de sangue provém do encéfalo, excetuando os tipos intraventriculares, são radiossensíveis. Os meningiomas multilobulares, cuja camada externa é firme e regular e cujos lóbulos são pálidos e moles no seu interior, e nos quais existem vasos sangǘneos na superfície e nos septos entre os lóbulos, são sensíveis. Os tumores sólidos, com uma superfície granular e vasos bem distribuídos em uma substância homogênea, são resistentes. A maioria dos meningiomas em placa, os tipos moles, igualmente, os tipos duros e pálidos, são sensíveis.

\section{ESCOLHA DO TRATAMENTO}

E' provável que todos os tumores do primeiro grupo sejam radiorresistentes. Êles crescem lentamente e não são influenciados, em nada, pela radioterapia. Entretanto, creio que se deve fazer duas exceções antes de afastar êste grupo de tumores, das nossas considerações. A primeira exceção é a do ependimoma localizado no sistema ventricular. particularmente no $3 .^{\circ} \mathrm{e} 4 .^{\circ}$ ventrículos, pois tivemos alguns casos de sucessos relativos. E' possível que tenhamos tido sucesso no tratamento de tumores diagnosticados como ependimoma, em virtude de uma interpretação histológica diferente. Não me lembro de um só caso que tenha sido diagnosticado como ependimoblastoma por Pollack, neuropatologista do Serviço do Prof. Jefferson. Se todos os ependimomas são classificados em um só grupo, é possível que tenhamos tratado tipos resistentes e, também, tipos sensíveis. De qualquer forma, uma vez 
que existe esta dificuldade, mais vale experimentar o efeito do tratamento em todo o tumor rotulado como ependimoma.

A outra exceção é a dos casos de tumores dêste grupo em doentes que mostram recidiva do tumor após ablação cirúrgica. Em tais casos, quando não se possa mais operar, pode-se obter ainda alguma melhora dos sintomas pelo uso da radioterapia, utilizando-se a técnica que será descrita para o segundo grupo.

O segundo grupo é considerado como radiossensível, mas os tumores não são senão relativamente sensíveis. Por outro lado, o encéfalo é, por si mesmo, sensível à irradiação e a diferença entre a sensibilidade dos tecidos normais e a do tumor é bem pequena. Há necessidade, nessas eventualidades, de agir sôbre o menor volume de tecido contendo o tumor. Nem sempre é fácil a determinação do volume do tumor. Se o cirurgião já retirou a maior parte do tumor, é necessário incluir na irradiação, também, todo o espaço que era ocupado pelo tumor, pois não se pode saber até que ponto ia a difusão das células neoplásticas. Se foi impossível a retirada do tumor, o neurocirurgião deverá avaliar o volume dêste pelo exame neurológico e pelos ventriculogramas. Quando somos chamados para aplicar a radioterapia nestes casos, pedimos ao neurocirurgião que desenhe os contornos do tumor em radiografias anteroposteriores e laterais, que permitem avaliar o seu volume. E' preciso, então, irradiar a parte do cérebro que contém o tumor e, mesmo, às vêzes, todo o cérebro, com as doses mais elevadas que possam ser toleradas. Neste grupo estão compreendidos, assim como os três tipos de tumores acima referidos, também os pinealomas e os hemangiomas. Os meningiomas, como já dissemos acima, constituirão problema até o momento em que possamos encontrar um meio de reconhecer-lhes os tipos sensíveis. Atualmente, minha opinião é de que se deve irradiar todos os meningiomas, pois não se pode prever a resposta. Dott aplica a radioterapia em todos os seus doentes mas, se não fôr notada qualquer melhora, o doente é encaminhado para ablação cirúrgica.

O terceiro grupo compreende apenas um tumor importante do ponto de vista de freqüência, o meduloblastoma; os outros três tipos de neoplasias são tão raros que nenhum dêles foi assinalado em oito anos de trabalho no Serviço do Prof. Jefferson. O característico dêstes tumores é que, na maioria das vêzes, êles são encontrados intimamente associados com o sistema ventricular; o meduloblastoma é mais freqüente na região cerebelar. Acontece freqüentemente que, em conseqüência dessa localização, êsses tumores produzem metástases no canal vertebral. O princípio no qual se baseia o tratamento dêstes tumores é a irradiação, em um só campo, de todo o sistema nervoso central, mesmo que 
não se tenha assinalado sintoma algum indicando a existência de metástases no momento em que é feito o diagnóstico.

Os tumores do quarto grupo são muito malignos e pertencem todos à classe dos sarcomas do cérebro. Como os outros sarcomas dos tecidos diferenciados, êles são resistentes, ainda que, algumas vêzes, se obtenha melhora imediata. Esta melhora, no entanto, não perdura muito e a maioria dèstes pacientes morre em menos de um ano.

Nós nos encontramos, agora, em face do problema oferecido pelos casos nos quais é impossível obter biópsia. Alguns dentre êles já terão sido operados por trepanação descompressiva, outros poderão estar em tão mau estado que a operação é julgada impossível. Se o doente fôr jovem, vale a pena iniciar uma tentativa de irradiação. Lembro-me de uma criança de 7 anos, caquética e internada em estado de coma, que se restabeleceu e que, atualmente, dois anos após o tratamento, ainda se conserva em bom estado. Quando o doente é mais idoso, às vêzes, pode ser obtido um resultado inesperado, mas a melhora não será mais que temporária. Recordo-me do caso de um homem de 50 anos, internado em estado de coma; após a irradiação, êle parecia quase normal mas, pouco tempo depois, se produziu uma hemorragia retal, que levou à descoberta de um câncer primário do colon.

Devo lembrar, agora, que o tumor cerebral pode ser uma metástase, localizando-se o insuspeitado tumor primário no pulmão, na mama ou no rim. Além disso, o radioterapeuta será, às vêzes, chamado para tratar a metástase cerebral depois de ter tratado o tumor primário. Mesmo nos casos mais graves, se o doente apresenta grande sofrimento ou se os seus olhos tenham sido atingidos, valerá a pena tentar os efeitos da irradiação, que podem produzir alívio temporário.

Os tumores pituitários não entram fàcilmente em nossa classificação. O tipo cromófobo é, às vêzes, admitido como sensível, mas não é essa a nossa opinião. Por outro lado, ainda que a maioria dos adenomas cromófilos se tenha mostrado resistente, já obtivemos, em numerosos casos, uma verdadeira melhora seguida de longo período de remissão. Se tôdas as possibilidades de intervenção cirúrgica foram cuidadosamente consideradas e afastadas, julgo que a radioterapia deve ser aplicada no tratamento dêstes tumores.

\section{TECNICA DO TRATAMENTO}

A radioterapia dos tumores cerebrais pode ser aplicada segundo cinco técnicas principais: 1. Irradiação do sistema nervoso inteiro; 2. Irradiação do cérebro inteiro; 3 . Irradiação dos campos médios por feixes orientados; 4. Irradiação paliativa; 5. Irradiação pituitária.

$O$ radioterapeuta deve levar em conta certos problemas técnicos associados com a absoŗ̧ão dos raios X pelos ossos e o efeito desta absor- 
ção sôbre a dose recebida pelo tumor. Mas não será necessário, aqui, abordar questões físicas. Descreverei nosso modo de proceder, sem entrar em detalhes quanto ao método.

Empregamos a primeira técnica -- irradiação do sistema nervoso inteiro - para o grupo dos tumores sensíveis que produzem metástases. A irradiação do cérebro inteiro é empregada nos casos de tumores radiossensíveis que não produzem metástases, nos casos em que êsses tumores não podem ser localizados fàcilmente. Consegue-se essa irradiação colocando dois campos laterais extensos sôbre a abóbada craniana com a adição de um só campo estreito inclinado verticalmente no sentido do plano sagital; a dose central é a dose máxima sôbre a pele: $4500 \mathrm{r}$ em 5 semanas. Uma outra disposição que distribui uma dose mais homogênea ao cérebro inteiro compreende três campos dispostos en triângulo eqüilátero sôbre um aparêlho simples, que nós denominamos de "head bridge", e que proporciona uma posição sempre correta dos campos.

A irradiação dos campos médios por feixe orientado é empregada para o grupo de tumores radiossensíveis quando é possível determinar-lhes exatamente a localização. Seu fim é o de diminuir a área irradiada, de modo a administrar, sem perigo, uma dose mais forte. Há necessidade de emprêgo de uma carapaça para feixes orientados, sôbre a qual se localizam os campos; êstes são de gêsso, com suportes de cera. $\mathrm{O}$ "back-pointer" adaptado à ampôla fixa o ponto de entrada e o ponto de saída do feixe. Para o tratamento com êstes campos médios parece ser mais útil uma dose de $5000 \mathrm{r}$ em 5 semanas.

A radioterapia paliativa é a única que pode ser usada nos casos de tumores resistentes muito malignos. Tratamentos complicados executados durante várias semanas são supérfluos e a disposição descrita para a irradiação do cérebro inteiro deve ser empregada, de modo a proporcionar um total de $2000 \mathrm{r}$ em quatro dias, ou $3000 \mathrm{r}$ em oito dias.

Os tumores pituitários são fáceis de tratar por causa de seu pequeno volume e de sua situação central. Êles se prestam à irradiação por meio de múltiplos pequenos campos com feixes orientados, podendo-se administrar doses de até $6000 \mathrm{r}$ em seis semanas. No entanto, não sabemos se há qualquer vantagem em ir além de $5000 \mathrm{r}$ em cinco semanas.

Antes de terminar, é necessário lembrar a possibilidade da necrose do cérebro provocada pela radioterapia. Antigamente, acreditava-se que o cérebro era extremamente resistente, mas hoje sabe-se que a dose tolerável é limitada, não sòmente pelo efeito da irradiação sôbre os vasos sangüíneos, mas também pela sua ação direta sôbre as células nervosas. O emprêgo do microscópio eletrônico mostrou modificações na substância lipóidica das bainhas de mielina e, provàvelmente, no interior das 
células nervosas; mesmo em preparações histológicas comuns observamse modificações atribuíveis a degenerescência, apesar do afluxo sangüíneo parecer estar intacto. A publicação de certo número de casos de necrose cerebral pós-radioterápica desencorajou alguns neurologistas. Segundo meu modo de ver, êste receio não tem razão de ser. Os tumores cerebrais são mortais se não fôrem devidamente tratados e, em cirurgia como em radioterapia, é preciso correr os riscos do tratamento. Se a dosagem fôr cuidadosamente controlada em níveis ligeiramente inferiores àqueles usados no tratamento dos epiteliomas e se doses completas fôrem administradas em uma única série de tratamento e nãao divididas em várias séries dadas com longos intervalos, haverá pouco risco de acidentes, e uma proporção considerável de doentes será grandementebeneficiada pelo tratamento.

Instituto de Radioterapia, Manchester - Inglaterra 